\title{
HUBUNGAN SIKAP REMAJA DENGAN PENGGUNAAN KONTRASEPSI PADA ANAK JALANAN DI PAMULANG PERMAI
}

\author{
Eka Mardiana Afrilia ${ }^{1}$ Yuyun Dwi Cahyanti ${ }^{2}$ \\ Fakultas Ilmu Kesehatan \\ Universitas Muhammadiyah Tangerang \\ Email: eka_afrilia@rocketmail.com
}

\begin{abstract}
ABSTRAK
Masa remaja merupakan masa peralihan dari masa anak-anak ke masa dewasa, yang meliputi semua perkembangan yang dialami sebagai persiapan memasuki masa dewasa. Dalam penelitian ini peneliti ingin mengetahui adakah hubungan sikap dengan penggunaan kontrasepsi pada anak jalanan di Pamulang Permai.Desain penelitian yang digunakan adalah deskriptif analitik dengan pendekatan Cross sectional. Sampel dalam penelitian ini adalah seluruh populasi yang berjumlah 30 responden dengan memenuhi kriteria anak jalanan yang berusia 18-22 tahun. Alat ukur yang digunakan adalah kuesioner dengan skala pengukuran dalam bentuk skala likert.Hasil penelitian disimpulkan berdasarkan uji chi square diperoleh nilai $\boldsymbol{\rho}$ value 0,002 yang berarti terdapat Hubungan yang bermakna antara sikap remaja dengan penggunaan kontrasepsi pada anaka jalanan di Pamulang Permai dan bersikap positif terhadap pemakaian kontrasepsi $(63,3 \%)$.Banyaknya remaja yang bersikap positif dalam penggunaan kontrasepsi karena itu remaja perlu diarahkan dan diberikan penyuluhan kesehatan reproduksi, pendidikan seksual dan pelayanan kesehatan reproduksi yang komprehensif dan terintregasi agar tidak bertentangan dengan norma, nilai dan kepercayaan masyarakat.
\end{abstract}

Kata kunci : sikap penggunaan kontrasepsi, kontrasepsi pada remaja

\section{PENDAHULUAN}

Masa remaja merupakan masa peralihan dari masa anak-anak ke masa dewasa, yang meliputi semua perkembangan yang dialami sebagai persiapan memasuki masa dewasa. Remaja adalah kelompok penduduk yang berusia 10-19 tahun (WHO) sementara menurut PBB adalah 1524 tahun. Sementara itu menurut The Health Resources of Services Administration Guidelines Amerika Serikat, rentang usia remaja 11-21 tahun dibagi menjadi tiga tahap, yaitu remaja awal (11-14 tahun), remaja menengah ( 1517 tahun) dan remaja akhir (18 - 21 tahun).

Badan Kependudukan dan Keluarga Berencana (BKKBN) menilai, perkembangan isu remaja khususnya perilaku remaja akhir-akhir ini sudah mengindikasi ke arah perilaku berisiko. Hal tersebut terlihat berdasarkan Survei Kesehatan Reproduksi Remaja (SKRR) tahun 2012 yang dilakukan oleh BKKBN. Bahkan dalam survei tersebut juga terungkap, umur berpacaran pertama kali paling banyak adalah usia 15-17 tahun, yakni pada 45,3 persen remaja pria dan 47,0 persen remaja wanita. Dari seluruh usia yang disurvei yakni 10-24 tahun, hanya 14,8 persen yang mengaku belum pernah pacaran sama sekali (BKKBN, 2012).

Tingginya kehamilan tidak diinginkan (KTD) erat kaitannya dengan tindakan tidak aman. Jumlah aborsi per tahun di Indonesia mencapai 2,4 juta dan sekitar 800.000 terjadi di kalangan remaja. Lembar 
fakta yang diterbitkan oleh PKBI, United Nation Population Fund Ascosiation (UNFPA) dan BKKBN menyebutkan bahwa setiap tahun terdapat sekitar 15 juta remaja berusia 15-19 tahun melahirkan, sekitar 2,3 juta kasus aborsi juga terjadi di Indonesia dimana $20 \%$ nya dilakukan oleh remaja. Fakta lain menunjukkan bahwa sekitar 15\% remaja usia 10-24 tahun yang jumlahnya mencapai 52 juta telah melakukan hubungan seksual diluar nikah. (Yunita,dkk.2013)

Badan Koordinasi Keluarga Berencana Nasional (BKKBN) tahun 2010 merilis data remaja yang sudah pernah melakukan hubungan seksual pranikah diantaranya, Jakarta sebesar 51\%, Bogor sebesar 51\%, Tangerang sebesar 51\%, Surabaya sebesar $54 \%$, Medan sebesar 52\%, Bandung sebesar 47\%, dan Yogyakarta sebesar 37\%. (Ganiajri, dkk, 2012). Dari penelitian yang dilakukan Musafah (2007) diperoleh data remaja pranikah yang menggunakan kontrasepsi terbanyak yaitu Pil 89,8 \%, Kondom 85,7\% dan kontrasepsi IUD 70, 4 $\%$. Dari uraian tersebut dapat disimpulkan bahwa perilaku seks bebas di kalangan remaja bukan lagi merupakan suatu issue tetapi telah dijadikan salah satu gaya hidup di kalangan remaja.

\section{METODE PENELITIAN}

Jenis penelitian ini adalah bersifat deskriptif analitik dengan pendekatan Cross sectional. Dalam penelitian ini, sampel diambil berdasarkan tehnik Accidental Sampling dimana siapa saja yang secara kebetulan bertemu dengan peneliti dapat digunakan sebagai sampel (Sugiyono, 2010). Jumlah sampel yang digunakan dalam penelitian ini berjumlah 30 responden yang memenuhi kriteria inklusi, yaitu:

1) Seluruh anak jalanan di Pamulang Permai.

2) Seluruh anak jalanan pranikah yang bersedia dijadikan responden dengan rentan usia (11-21 tahun).

3) Seluruh anak jalanan pranikah yang hadir saat pengambilan data dengan rentan usia (11-21 tahun).
Penelitian ini dilakukan di Pamulang Permai pada Maret-Mei 2017. Pada penelitian ini instrumen atau alat ukur yang digunakan adalah kuesioner. Skala pengukuran yang digunakan dalam penelitian ini dalam bentuk Skala Likert. Skala Likert yang dipergunakan dengan skala pengukuran adalah Sangat Setuju (SS), Setuju (S), Tidak Setuju (TS), Sangat Tidak Setuju (STS). Tiap jawab diberi bobot berkisar antara 4-1, yang disesuaikan dengan sifat pertanyaan. Sebagian dari pertanyaan itu menunjukkan pendapat yang positif maupun negatif. Analisis data menggunakan analisa statistik dengan menggunakan uji data chi-square pada tingkat kemaknaannya $(\mathrm{p}<0,01)$ sehingga dapat diketahui ada tidaknya hubungan yang bermakna secara statistik dengan menggunakan program komputer SPSS.

\section{HASIL}

\section{Analisa Univariat}

Tabel 1

Distribusi frekuensi berdasarkan usia responden remaja anak jalanan di Pamulang Permai.

\begin{tabular}{|c|c|c|c|}
\hline $\begin{array}{c}\text { Usia } \\
\text { Responden }\end{array}$ & Frekuensi & & \% \\
\hline Remaja Awal & 21 & & 70 \\
\hline Remaja Akhir & 9 & & 30 \\
\hline Jumlah & 30 & & 100 \\
\hline
\end{tabular}

Berdasarkan tabel 1 dapat diketahui bahwa mayoritas usia remaja pada kategor remaja awal yaitu $21(70 \%)$ remaja.

Tabel 2

Distribusi frekuensi sumber informasi responden anak jalanan di Pamulang Permai.

\begin{tabular}{|c|c|c|}
\hline $\begin{array}{c}\text { Sumber } \\
\text { Informasi }\end{array}$ & Frekuensi & $\boldsymbol{\%}$ \\
\hline Media Cetak & 15 & 50 \\
\hline Media Elektronik & 15 & 50 \\
\hline Total & $\mathbf{3 0}$ & $\mathbf{1 0 0}$ \\
\hline
\end{tabular}


Berdasarkan tabel 4.2 dapat diketahui bahwa sumber informasi remaja dari media cetak dan elektronik masing-masing 15 $(50 \%)$.

Tabel 3

Distribusi frekuensi sikap terhadap pemakaian kontrasepsi pada remaja anak jalanan di Pamulang Permai.

\begin{tabular}{|c|c|c|}
\hline Sikap Remaja & Frekuensi & $\%$ \\
\hline Positif & 19 & 63.3 \\
\hline Negatif & 11 & 36.7 \\
\hline Total & 30 & 100 \\
\hline
\end{tabular}

Berdasarkan tabel 3 dapat diketahui bahwa mayoritas siswa memiliki sikap positif terhadap pemakaian kontrasepsi yaitu sebanyak 19 (63.3\%) remaja.

Tabel 4

Distribusi frekuensi penggunaan kontrasepsi pada remaja anak jalanan di Pamulang Permai

\begin{tabular}{|c|c|c|}
\hline $\begin{array}{c}\text { Jenis } \\
\text { Kontrasepai }\end{array}$ & Frequensi & $\%$ \\
\hline $\begin{array}{c}\text { Tidak } \\
\text { menggunakan } \\
\text { kontrasepsi }\end{array}$ & 9 & 30 \\
\hline Ejakulasi diluar & 11 & 36,7 \\
\hline KB Suntik & 1 & 3,3 \\
\hline Kondom & 7 & 23,3 \\
\hline Pil & 2 & 6,7 \\
\hline Total & 30 & 100.0 \\
\hline
\end{tabular}

Berdsarkan tabel 4.4 dapat diketahui bahwa mayoritas remaja menggunakan jenis kontrasepsi KB ejakulasi diluar yaitu $11(36,7 \%)$ remaja, kondom $7(23,3 \%)$ remaja, Pil $2(6.7 \%)$ remaja, dan suntik 1 $(3,3 \%)$ remaja.

\section{Analisis Bivariat}

Tabel 5

Hubungan antara sikap remaja dengan penggunaan kontrasepsi pada anaka jalanan di Pamulang

Permai.

\begin{tabular}{|c|c|c|c|c|c|c|c|}
\hline \multirow{3}{*}{ Sikap } & \multicolumn{4}{|c|}{$\begin{array}{l}\text { Penggunaan } \\
\text { Kontrasepsi }\end{array}$} & \multirow{2}{*}{\multicolumn{2}{|c|}{ Total }} & \multirow[b]{2}{*}{$\begin{array}{c}P \\
\text { value }\end{array}$} \\
\hline & \multicolumn{2}{|c|}{$\begin{array}{l}\text { Mengguna } \\
\text { kan }\end{array}$} & \multicolumn{2}{|c|}{$\begin{array}{c}\text { Tidak } \\
\text { Menggu } \\
\text { nakan }\end{array}$} & & & \\
\hline & $\mathbf{F}$ & $\%$ & $\mathbf{F}$ & $\%$ & $\mathbf{F}$ & $\%$ & \multirow{4}{*}{0.002} \\
\hline Positif & 17 & 89.5 & 2 & 10.5 & 19 & 100 & \\
\hline Negatif & 4 & 36.4 & 7 & 63.6 & 11 & 100 & \\
\hline Total & 21 & 70 & 9 & 30 & 30 & 100 & \\
\hline
\end{tabular}

Berdasarkan tabel 5 hasil Analisis Bivariat yang telah dilakukan menggunakan uji chi square diperoleh nilai $\boldsymbol{\rho}$ value 0,002 , maka dapat disimpulkan $\boldsymbol{\rho}$ value $<\alpha$ sehingga Ha diterima yang berarti terdapat Hubungan antara sikap remaja dengan penggunaan kontrasepsi pada anak jalanan di Pamulang Permai.

\section{PEMBAHASAN}

Berdsarkan tabel 1 dapat diketahui bahwa mayoritas usia remaja pada kategori remaja awal yaitu $21 \quad(70 \%)$ remaja sedangkan usia remaja kategori remaja akhir yairu sebanyak 9 (30\%) remaja.

Masa remaja merupakan salah satu periode dari perkembangan manusia. Masa ini merupakan masa perubahan atau peralihan dari kanak-kanak ke masa dewasa yang meliputi perubahan biologik, perubahan psikologik, dan perubahan sosial. Di sebagian besar masyarakat dan budaya masa remaja pada umumnya dimulai pada usia 10-13 tahun dan berakhir pada usia 18-22 tahun (kusmiran, 2011 :4).

Umur, menurut Elizabet B.H, (1995), umur adalah umur individu yang terhitung mulai saat dilahirkan sampai saat berulang tahun. Menurut (Hurlock, 1998) yang dikutip dari Nursalam dan Siti Pariyani (2001: 134) semakin umur tingkat kematangan dan ketakutan, seseorang akan lebih matang dalam berfikir dan bekerja dari segi kepercayaan masyarakat. Seseorang akan lebih dewasa akan lebih percaya dari orang yang belum cukup tinggi kedewasaannya, hal ini sebagai akibat dari pengalaman dan kematangan jiwa.

Dari tabel 2 dapat diketahui bahwa sumber informasi remaja dari media cetak dan elektronik masing-masing 15 (50\%). Menurut BKKBN 2007 informasi 
mengenai alat kontrasepsi sangat penting dipahami sebelum memutuskan menggunakan alat kontrasepsi tertentu. Hal ini serupa dengan pendapat BAPPENAS yaitu dengan berbekal pengetahuan mengenai alat-alat kontrasepsi, beserta efek samping yang ditimbulkannya, kontraindikasi, kekurangan, dan kelebihannya. Masyarakat dapat menentukan pilihan alat kontrasepsi yang sesuai sehingga memberi pengayoman lebih tinggi yang akhirnya akan meningkatkan kelestariannya dalam berkeluarga berencana. Jadi pengetahuan mengenai alat-alat kontrasepsi beserta efek samping, kontraindikasi, kekurangan, dan kelebihan sangat diperlukan untuk menentukan pilihan alat kontrasepsi yang akan digunakan serta untuk mendukung program Repelita V yaitu agar masyarakat lebih menggunakan alat kontrasepsi yang efektif.

Berdasarkan tabel 3 dapat diketahui bahwa mayoritas siswa memiliki sikap positif terhadap pemakaian kontrasepsi yaitu sebanyak $19 \quad(63.3 \%)$ remaja sedangkan remaja yang memililki sikap negatif yaitu sebanyak 11 (36.7\%).

Sikap adalah evaluasi umum yang dibuat manusia terhadap dirinya sendiri, orang lain, obyek atau issue (Petty, cocopio, 1986 dalam Azwar S, 2000: 6). Atau kecenderungan bertindak dari individu, berupa respons terhadap stimulus ataupun objek tertentu (Sunaryo, 2004). Sikap bisa juga berupa kecenderungan seseorang terhadap objek mendukung atau tidak mendukung, seperti yang diungkapkan oleh Azwar (2007) "Sikap seseorang terhadap suatu objek adalah perasaan mendukung atau memihak maupun perasaan tidak mendukung atau tidak memihak pada objek tersebut".

Berdsarkan tabel 4 dapat diketahui bahwa mayoritas remaja menggunakan jenis kontrasepsi $\mathrm{KB}$ ejakulasi diluar yaitu $11(36,7 \%)$ remaja, kondom $7(23,3 \%)$ remaja, Pil $2(6.7 \%)$ remaja, dan suntik 1 $(3,3 \%)$ remaja.
Menurut KKB (2011) metode kontrasepsi bekerja dengan dasar mencegah sperma laki-laki mencapai dan membuahi telur wanita (fertilisasi) atau mencegah telur yang sudah dibuahi untuk berimplantasi (melekat) dan berkembang di dalam rahim.

Dari tabel 5 menunjukan dari 19 remaja yang memiliki sikap positif dengan sebanyak 17 (89.5\%) remaja menggunakan alat kontrasepsi dan $2(10.5 \%)$ remaja tidak menggunakan alat kontrasepsi. Dari 11 remaja yang memiliki sikap negatif dengan sebanyak $4(36.4 \%)$ remaja menggunakan alat kontrasepsi dan 7 (63.6\%) remaja tidak menggunakan alat kontrasepsi.

Hasil Analisis Bivariat yang telah dilakukan menggunakan uji chi square diperoleh nilai $\boldsymbol{\rho}$ value 0,002 maka dapat disimpulkan $\boldsymbol{\rho}$ value $<\alpha$ sehingga $\mathrm{Ha}$ diterima yang berarti terdapat Hubungan antara sikap remaja dengan penggunaan kontrasepsi pada anaka jalanan di Pamulang Permai.

Berbeda dengan hasil penelitian menunjukkan bahwa tidak ada hubungan yang signifikan antara pengetahuan dengan sikap terhadap pemakaian kontrasepsi. Menurut Musafah (2007) Pengetahuan dan Sikap Pemakaian Kontrasepsi pada Remaja "GAUL" di Parkir Senayan, Jakarta. Hasil penelitian menunjukkan tidak sesuai dengan Musafah. Pengetahuan seksual dan kesehatan reproduksi khususnya kontrasepsi yang setengah-setengah tidak hanya mendorong remaja mencoba-coba tetapi juga menimbulkan salah persepsi.

Namun sejalan dengan hasil penelitian yang dilakukan Sutanti (2012) ada hubungan sikap dengan pemilihan kontrasepsi IUD pada wanita usia subur di Desa Sepanjang Wilayah Kerja Puskesmas Sepanjang Kecamatan Glenmore tahun 2013. Sikap adalah salah satu faktor predisposisi yang merupakan pendorong perilaku seseorang untuk bertindak (Green dalam Notoatmodjo, 2010). Dalam penelitian ini sikap remaja seringkali mengacu pada pengalaman teman sebaya yang belum tentu pengalaman itu benar dan 
sehat. Karena pengaruh teman sebaya lebih besar berpraktik buruk, maka merekapun akan mengikutinya dan akhirnya praktik kesehatan reproduksinya buruk.

\section{KESIMPULAN}

Berdasarkan hasil penelitian yang dilakukan penulis tentang Hubungan Sikap Remaja Dengan Penggunaan Kontrasepsi Pada Anak Jalanan di Pamulang Permai Tahun 2017, maka dapat diambil kesimpulan :

1. Distribusi frekuensi berdasarkan usia responden pada kategori remaja awal yaitu $21(70 \%)$ remaja sedangkan usia remaja kategori remaja akhir yaitu sebanyak $9(30 \%)$ remaja.

2. Distribusi frekuensi berdasarkan sumber informasi responden bahwa sumber informasi remaja dari media cetak dan elektronik masing-masing 15 (50\%).

3. Distribusi frekuensi berdasarkan pengguna kontrasepsi mayoritas remaja menggunakan jenis kontrasepsi $\mathrm{KB}$ ejakulasi diluar yaitu $11(36,7 \%)$ remaja, kondom 7 (23,3\%) remaja, Pil 2 (6.7\%) remaja, dan suntik $1(3,3 \%)$ remaja.

4. Distribusi frekuensi berdasarkan sikap remaja dengan penggunaan kontrasepsi mayoritas remaja bersikap positif terhadap pemakaian kontrasepsi yaitu sebanyak $19(63,3 \%)$ remaja dan yang memiliki sikap negatif $11(36,7 \%)$ remaja.

5. Ada hubungan yang bermakna antara sikap dengan penggunaan kontrasepsi pada anak jalanan di Pamulang Permai dengan nilai $\boldsymbol{\rho}$ value $0,002<\alpha$.

\section{SARAN}

1. Bagi anak jalanan di Pamulang Permai dapat sebagai pertimbangan untuk diri sendiri agar lebih menjaga kesehatan reproduksinya terutama menghindari seks bebas.

2. Bagi pemerintah perlu lebih memperhatikan dengan lebih serius kebijakan tentang anak jalanan khususnya masalah kesehatan reproduksi serta membuat program yang efektif terhadap penyaluran informasi kesehatan reproduksi pada anak jalanan.

3. Bagi masyarakat khususnya para orang tua untuk lebih memahami perilaku anak agar lebih bisa membimbing atau memberi arahan kepada anak-anaknya tentang pengetahuan perilaku seksual .

4. Bagi nakes perlunya ketersediaan akses layanan kesehatan reproduksi berhubungan dengan perilaku seks diharapkan dapat membuat suatu program yang berfokus pada kesehatan reproduksi remaja, demi memberikan informasi dan edukasi tentang berbagai masalah kesehatan reproduksi pada remaja.

5. Bagi seluruh remaja penelitian ini diharapkan dapat memberikan informasi mengenai hubungan sikap dengan penggunaan kontrasepsi sehingga lebih bisa menjaga diri dalam pergaulan dan menjaga kebersihan organ reproduksi remaja.

6. Bagi institusi dapat memfasilitasi mahasiswa untuk memberikan penyuluhan kesehatan reproduksi bagi para anak jalanan dan menyiapkan wadah pengaduan bagi anak jananan yang ingin berkonsultasi mengenai kesehatan reproduksi.

\section{DAFTAR PUSTAKA}

Arikunto.( 2006). Prosedur Penelitian Suatu Pendekatan Praktik Klinik. Jakarta: PT. Rineka Cipta

BKKBN. (2010). Data Survey Kesehatan Reproduksi Indonesia. Jakarta

Dinkes Kabupaten Banten. (2010). Laporan Tahunan

Djaali, H. (2008). Psikologi Pendidikan. Jakarta:Bumi Aksara

Gianjri, dkk. (2012). Perbedaan Pemanfaatan Multimedia Flash Dan Ceramah Sebagai Media Pendidikan Kesehatan Reproduksi Remaja Bagi Remaja Awal di SMPN 3 Turi, Sleman. 1(1) 
Hartanto. 2009. Seks Bebas Dikalangan Remaja Menghawatirkan. Di akses di http://sufihjuwita.blogs.uny.ac.id/2015/ 12/17/free-sex-dikalangan-remaja. pada tanggal 15 Februari 2017 pukul 22:15 wib

Inayatullah. 2016. Profil Kesehatan Kabupaten Tangerang 2014. Di akses di http://dinkes.tangerangkab.go.id/wpcontent/files/Profil_Kesehatan_Kabupat en_Tangerang_2015.pdf . Tanggal 16 Februari 2017 pukul 11:15 Wib

KKB. (2011). Buku Panduan Praktis Pelayanan Kontrasepsi . Jakarta: PT. Bina Pustaka
Kusmiran, Eny. (2011). Kesehatan Reproduksi Remaja Dan Wanita. Jakarta: Salemba Medika

Notoatmodjo, S. (2010). Metodologi Penelitian Kesehatan. Jakarta: PT. Rineka Cipta

Septian. 2012. Pergaulan Remaja Mengarah ke Seksual. Diakses https://kesehatanreproduksiremaja.word press.com di akses pada tanggal 15 Februari 2017 pukul 20:00 wib

Yunita, dkk. (2013). Hubungan Pendidikan, Sumber Informasi Metode Kontrasepsi, Dan Dukungan Keluarga Dengan Penggunaan Metode Kontrasepsi Pasangan Usia Subur Berusia <20 Tahun. 1(3). 